\title{
PRELIMINARY STUDY OF WATER INJECTION ON THE COMBUSTION AND EMISSIONS CHARACTERISTICS IN A HCCI ETHANOL ENGINE
}

\author{
G. D. Telli ${ }^{\mathbf{a}}$, \\ G. Y. Zulian ${ }^{\mathrm{b}}$, \\ S. R. Stefanello ${ }^{b}$, \\ T. D. M. Lanzanovab, \\ M. E. S. Martins ${ }^{b}$ \\ and L. A. O. Rocha ${ }^{\mathrm{c}, \mathrm{a}}$ \\ ${ }^{a}$ Universidade Federal do Rio Grande do Sul \\ Rua Sarmento Leite, 425 Porto Alegre, \\ Rio Grande do Sul, Brasil \\ giovani.telli@gmail.com \\ bUniversidade Federal de Santa Maria \\ Av. Roraima, 1000, Santa Maria \\ Rio Grande do Sul, Brasil \\ guilherme.zuliaan@gmail.com \\ sergio.stefanello@gmail.com \\ lanzanova@mecanica.ufsm.br \\ mario@mecanica.ufsm.br \\ 'Universidade do Vale do Rio dos Sinos \\ Av. Unisinos, 950, São Leopoldo \\ Rio Grande do Sul, Brasil \\ laorocha@gmail.com \\ Received: Dec 04, 2020 \\ Revised: Dec 18, 2020 \\ Accepted: Dec 20, 2020
}

\begin{abstract}
Our dependence on fossil fuels coupled with concerns about harmful emissions have motivated researchers to look for renewable fuels that have clean combustion and for advanced combustion modes. In this context, homogeneous charge compression ignition (HCCI) is an emerging technology which offers an alternative to conventional spark ignition and compression ignition engines and can operate on renewable fuels. Low temperature combustion, which can result in low NOx emissions with high indicated efficiency, is the more important characteristic of this combustion mode. It's main problem is the combustion timing control due to lack of direct ignition control, once HCCI flame initiation is based on charge thermal state. Thus, controlled auto-ignition (CAI) combustion mode has been proposed. Several methods were proposed for combustion phasing control, between them, the injection of water in the intake manifold. This work investigated the influence of water injection in the intake runner of an ethanol HCCI cylinder from a converted three-cylinder diesel generator set, in which two cylinders operated on conventional diesel combustion and one diesel cylinder provided recycled exhaust gas for the one cylinder running on ethanol HCCI combustion. The water injection was used to control the CA50 combustion parameter. The results show that water injection is an efficient strategy to control the combustion timing, since the reactivity of the mixture can be controlled. The results at 400 and $600 \mathrm{kPa}$ of IMEP and $1800 \mathrm{rpm}$ indicated a good combustion stability, high efficiency and low emissions characteristics. The highest indicated fuel conversion efficiency found was $36.9 \%$ for $600 \mathrm{kPa}$ of IMEP and $8 \mathrm{CAD}$ of CA50. However, for $200 \mathrm{kPa}$ of IMEP the combustion was unstable, the indicated efficiency was deteriorated and indicted $\mathrm{CO}$ emissions was high.
\end{abstract}

Keywords: homogeneous charge compression ignition (HCCI); controlled auto ignition (CAI); water injection; ethanol; combustion

\section{NOMENCLATURE}

AHRR apparent heat release rate, $\mathrm{J} / \mathrm{CAD}$

BTDC before top dead center

CAD crank angle degree. ${ }^{\circ}$

CAI controlled auto ignition

CDC conventional diesel combustion

$\mathrm{COV}$ coefficient of variation

C_diesel diesel consumption, $\mathrm{g} / \mathrm{s}$

C_ethanol ethanol consumption, $\mathrm{g} / \mathrm{s}$

$\mathrm{DI} \quad$ direct injection

EGR exhaust gas recirculation

EGT exhaust gas temperature, ${ }^{\circ} \mathrm{C}$

FTIR fourier transform infrared spectroscopy

HCCI homogeneous charge compression ignition

ICE internal combustion engine

IMEP indicated mean effective pressure, $\mathrm{kPa}$

ISCO indicated specific emissions of $\mathrm{CO}, \mathrm{g} / \mathrm{kWh}$

ISHC indicated specific emissions of $\mathrm{HC}, \mathrm{g} / \mathrm{kWh}$

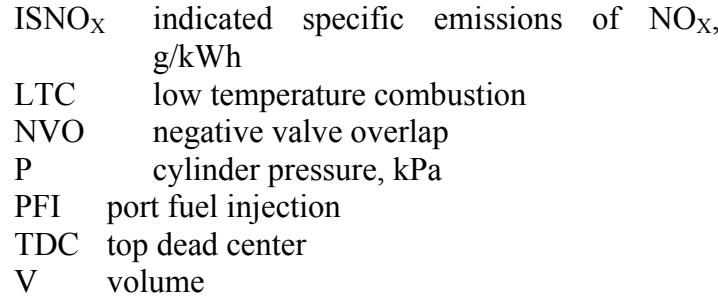

Greek symbols

$\theta \quad$ crank angle degree, ${ }^{\circ}$

$\gamma \quad$ ratio of specific heats, dimensionless

$\lambda$ relative air fuel ratio, dimensionless

\section{INTRODUCTION}

Internal combustion engines (ICE) are widely used worldwide, especially in the transport sector, 
where ICEs are the primary power horse. According to reports from International Energy Agency (IEA, 2019a and IEA 2019b), the transport sector was the main fossil oil consuming sector in 2017, resulting in $25 \%$ of all $\mathrm{CO}_{2}$ emissions in the atmosphere that contribute to the greenhouse effect. These data lead to concerns about global warming, atmospheric pollution, and health hazards (Punov et al., 2017). Another concern is that fossil fuel resources are limited and declining over time. This fact may increase fossil fuel prices while its consumption steadily rises due to population growth and improvements for better life quality (Mittal et al., 2015; U.S. Energy Information Administration, 2015). Therefore, special attention has been addressed to the study of renewable fuels to replace fossil fuels, especially in internal combustion engines, which are equipment very present in the current society, both for vehicle propulsion and for electric power generation (Vailatti et al., 2017; Rosa et al., 2019).

The automotive industry urgently requires cleaner and efficient technologies, capable of reducing pollutants and harmful emissions, and improving the utilization of energy (Agarwal, Singh and Maurya, 2017). The stringent emission legislation and scarcity of primary energy resources have motivated the research of new combustion concepts that are highly efficient, environment friendly, and capable of using alternative and renewable fuels. In recent years, researches have focused on low-temperature combustion (LTC), which is an emerging technology and has demonstrated the potential to enable engines to meet the forthcoming stricter emissions legislation. Concomitantly, it may provide higher engine operational efficiencies than conventional combustion modes, and it is possible to run with flexible fuels (Srivastava et al., 2018; Krishnamoorthi et al., 2019).

The most common technique of LTC is homogeneous charge compression ignition (HCCI) combustion, the fuel and air should be homogeneously mixed before combustion starts. The ignition process occurs spontaneously when the charge's auto ignition thermal state is reached at the end of the compression stroke. Intake air heating, residual gas trapping, exhaust gas recirculation (EGR), and high compression ratios have been explored as methods to increase charge temperature near TDC in order to promote CAI.

HCCI combustion mode based on the simultaneously auto ignition of the entire cylinder charge at multiple locations, resulting in a shorter combustion duration. Thus, it approximates a constant volume combustion and achieves relatively higher thermal efficiency (Agarwal, Singh and Maurya, 2017). Moreover, HCCI engines has the potential to reduce the $\mathrm{NO}_{\mathrm{X}}$ formation, since the maximum in-cylinder temperature in $\mathrm{HCCI}$ engines is lower than in SI and CI engines, which decreases NOx formation (Martins et al., 2017).

In HCCI engines, there are many challenges to overcome, such as combustion timing control, low power output, high levels of $\mathrm{CO}$ and $\mathrm{HC}$ emissions, and homogeneous mixture preparation (Bendu and Murugan, 2014; Saxena and Bedoya, 2013). The main challenge in HCCI engines is to control the combustion timing to expand its operating limits in a controlled manner. The difficulty is to ensure that the auto ignition occurs close to the top dead center (TDC) for a wide operation range. Besides, HCCI combustion is very fast, with high heat release rates, causing high-pressure gradients and knocking combustion (Valero-Marco et al., 2018). A few combustion phasing control techniques, such as using water injection to modulate the intake charge temperature, solve these difficulties.

Iwashiro et al. (2002) studied the direct incylinder water injection in a naturally aspired HCCI engine fueled with DME and propane. The results indicated that direct in-cylinder water injection increased indicated thermal efficiency of about $2 \%$, and the operation range was expanded from $460 \mathrm{kPa}$ to $700 \mathrm{kPa}$, maintaining a low NOx level. On the other hand, direct water injection increased $\mathrm{HC}$ and $\mathrm{CO}$ emissions, especially at the earliest injection timing.

Valero-Marco et al. (2018) investigated the use of direct water injection in an HCCI gasoline engine operating between $350 \mathrm{kPa}$ and $1000 \mathrm{kPa}$ at 1500 rpm. Water was directly injected into the combustion chamber as a reactivity suppressor to extend the knock-constrained load range of CAI operation. The CAI combustion was achieved using negative valve overlap (NVO) to trap hot residual gases inside the cylinder in order to achieve a fuel auto ignition state. Results showed that water injection was an efficient strategy to control the mixture reactivity and expand the engine's load range. It reduced in-cylinder pressure rise rates and the knock tendency while keeping combustion stability at acceptable levels. The results also indicated an increase in indicated thermal efficiency with NOx emissions reduction.

Ahari and Neshat (2019) theoretically investigated the effects of water addition on natural gas HCCI combustion using a thermodynamic multizone model coupled to a semi-detailed chemical kinetics mechanism. The authors studied five different quantities of water added to the fuel. The water was added to the in-cylinder charge while maintaining the total amount of mass inside the combustion chamber and the overall air-fuel ratio constant. It was found that the addition of water retards the start of combustion and decreases peak values of in-cylinder pressure and heat release rate. Besides that, water injection up to $3 \%$ on a mass basis increases the engine thermal efficiency and decreases exhaust emissions. The results 
demonstrated that the injection of water might help control an HCCI engine's combustion process.

In this regard, this paper aims to study experimentally the potential of water injection on the combustion and emissions characteristics of an HCCI engine cylinder fueled with ethanol. This paper presents the ethanol HCCI operation with water injection using direct exhaust heat recovery from another diesel cylinder exhaust gas. The modified engine operated with cylinder \#1 running on ethanol HCCI combustion mode attained via total recirculation of exhaust gas from cylinder \#3, which run on conventional diesel combustion (CDC) mode. Cylinder \#2 was also run on CDC and used to motor the setup and keep the generator set output load constant.

Since CDC operates with lean combustion, the cylinder \#1 diesel EGR stream is composed by heated air and the CDC combustion products. Thus, cylinder \#1 EGR is the major heat source for the auto ignition of the ethanol cylinder. The motivation of this paper is to assess the use of low carbon and renewable fuel such as ethanol in partial substitution of diesel fossil fuel to reduce fossil fuel dependence, pollutants, and harmful emissions to human health.

\section{METHODOLOGY}

A four-stroke water cooled naturally aspirated three cylinder MWM D229 diesel engine was modified for the present experiments. The specifications of unmodified and modified cylinders are given in Tab 1 . The engine was coupled to a WEG electric generator. The generator set operated at a constant speed of $1800 \mathrm{rpm}$, providing a constant brake load of $10 \mathrm{~kW}$ of electric power. The electric energy produced was dissipated on electric resistances immersed in cooled water.

Cylinder \#1 was isolated to run solely on ethanol with port fuel injection (PFI). The two remaining cylinders were kept running on conventional diesel combustion through a single direct injection (DI). The HCCI combustion in cylinder \#1 was attained via the total recirculation of exhaust gases from cylinder \#3. Thus, cylinder \#2 and \#3 have ambient air delivered to its intake, distinctively to cylinder \#1. All the exhaust gas from cylinder \#3 was delivered to a plenum connected to the intake pipe from cylinder \#1. Ethanol and water were injected in the plenum using two separate port fuel injectors. A schematic diagram of the experimental setup is shown in Fig. 1.

Table 1. Detailed engine specifications

\begin{tabular}{|c|c|c|}
\hline Engine characteristics & Standard & Modified \\
\hline Cylinder & 2 and 3 & 1 \\
\hline Ignition & CI & HCCI \\
\hline Injection system & DI & PFI \\
\hline Fuel & Diesel & Ethanol \\
\hline Compression ratio & $16: 1$ & $14: 1$ \\
\hline
\end{tabular}

\begin{tabular}{|c|c|}
\cline { 2 - 2 } Bore x Stroke $(\mathrm{mm})$ & $102 \times 120$ \\
\hline Rod Length $(\mathrm{mm})$ & 207 \\
\hline Swept Volume $\left(\mathrm{cm}^{3}\right)$ & 980.3 \\
\hline Engine Speed $(\mathrm{rpm})$ & 1800 \\
\hline
\end{tabular}

A programmable Megasquirt ECU was used to control the ethanol and water injected at the plenum. The diesel fuel injected at cylinder \#2 and \#3 used the engine's standard injection system. The diesel and ethanol flow rates were measured using two graduated burettes with $0.2 \mathrm{ml}$ resolution, and for time measurement, a chronometer was used. Consumption of $30 \mathrm{ml}$ was measured three times to ensure data confiability.

The excess of air ratio was measured using two wideband universal gas oxygen sensor, model LSU 4.2 Bosch brand. The gas oxygen sensors were fixed at the exhaust pipe of cylinder \#3 and before the ethanol mixing plenum. The cylinder \#1 exhaust and intake temperature, the cylinder \#3 exhaust gas temperature and plenum temperature were measured with K-type thermocouples. The equipment has a measuring range between $-50{ }^{\circ} \mathrm{C}$ and $1300{ }^{\circ} \mathrm{C}$, with resolution of $0.1{ }^{\circ} \mathrm{C}$ and uncertainty of $0.4 \%$ or 1.1 ${ }^{\circ} \mathrm{C}$. The intake and exhaust pressure from HCCI cylinder were measured using manifold pressure transducers MPX4250AP. To measure the concentrations of exhaust gaseous emissions of the HCCI cylinder, an AVL fourier transform infrared spectroscopy (FTIR) gas analyzer was used. A total of 24 species were measured simultaneously, with the most important groups as $\mathrm{CO}, \mathrm{CO}_{2}, \mathrm{NO}_{\mathrm{X}}$ and $\mathrm{HC}$.

In-cylinder pressure was measured using a piezoelectric transducer AVL GH14D and a Flex IFEM piezoelectric conditioner, while the crank angle was referenced by an incremental 0.2 crank angle degree resolution optical encoder. The incylinder pressure and crank angle were acquired by a National Instruments PCI 6024E data acquisition board with a 16-bit resolution. Crank angle based data was acquired in 100 cycles batches, and the discussed data is the angle based average of the 100 cycles. An in-house data acquisition and online combustion analysis LabVIEW based program was used. The recorded data was stored and post processed on Matlab.

The combustion parameters of the HCCI cylinder were calculated according to the apparent heat release rate as shown in Eq. (1):

$$
\frac{\mathrm{dQ}}{\mathrm{d} \theta}=\frac{1}{\gamma-1} \mathrm{~V} \frac{\mathrm{dP}}{\mathrm{d} \theta}+\frac{\gamma}{\gamma-1} \mathrm{P} \frac{\mathrm{dV}}{\mathrm{d} \theta}
$$

where $\gamma$ is the ratio of specific heats, $P$ is the cylinder pressure, $V$ is volume, and $\theta$ is the crank angle. Based on Eq. 1, the mass fraction burned can be integrated to evaluate the moments (in crank angle 
basis) of $10 \%, 50 \%$, and $90 \%$ of the burned mass, respectively designated by CA10, CA50, and CA90. CA10 was defined as the crank angle at which $10 \%$ of the heat energy from the air-fuel mixture is released in the cylinder, and it is an indication of the start of combustion. The CA90 is an indication of the end of combustion, representing the crank angle where $90 \%$ of the heat energy was released. In this regard, the combustion duration is the difference between CA10 and CA90.

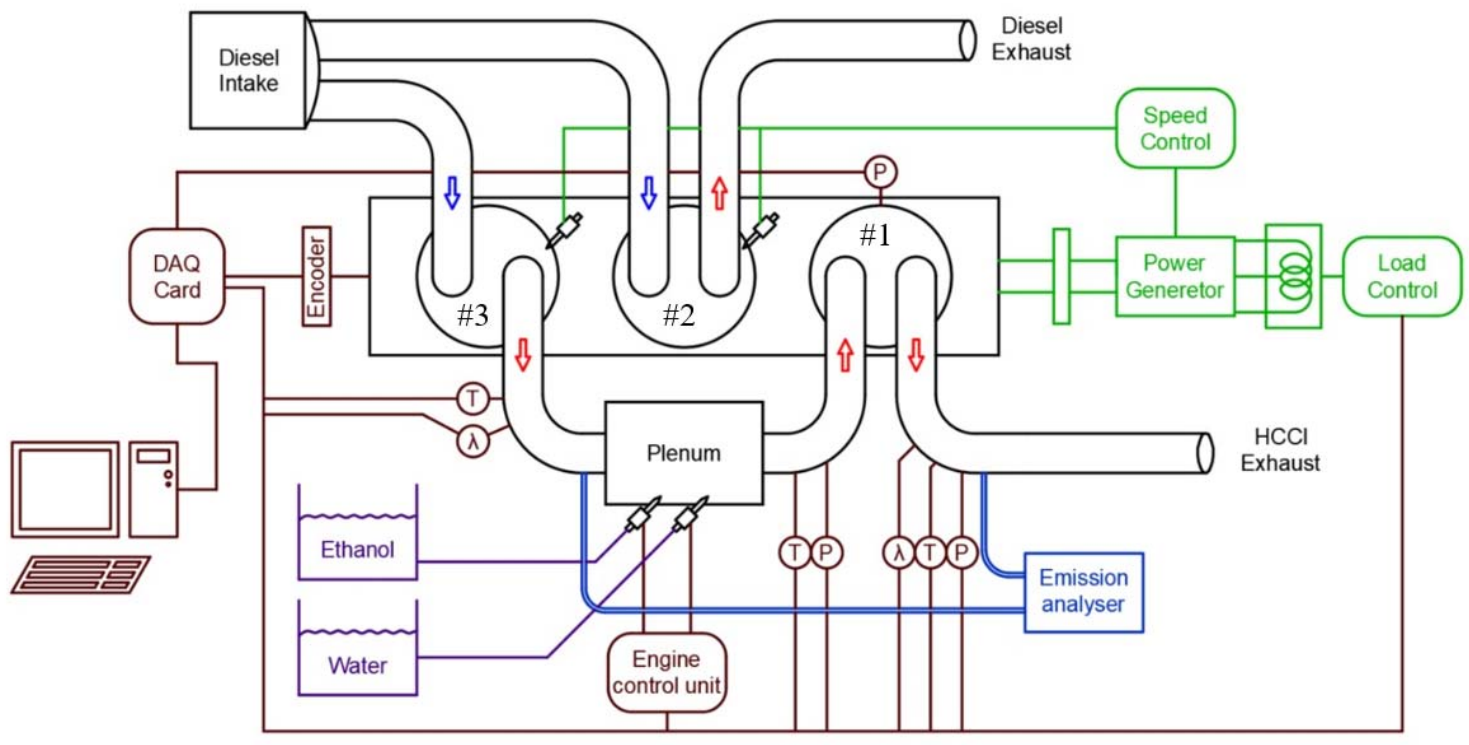

Figure 1. Schematic diagram of experimental setup.

The intake pressure of the HCCI cylinder was a consequence of the cylinder \#1 combustion, interestingly ranging around $140 \mathrm{kPa}$. In this experimental setup, the HCCI combustion without water injection in cylinder \#1 tended to start before TDC, resulting in knocking. In this sense, to evaluate the potential effects of water injection to control the combustion process of the HCCI cylinder, experiments were carried out for IMEP loads of 200 $\mathrm{kPa}, 400 \mathrm{kPa}$, and $600 \mathrm{kPa}$, wherein each one of them four CA50 points was achieved with water injection, 2, 4, 6 and 8 CAD. The generator BMEP load was kept constant due to the stock diesel injector governor, which controlled diesel cylinders load to keep the speed constant at $1800 \mathrm{rpm}$.

\section{RESULTS AND DISCUSSIONS}

The operating conditions of the test are presented in Tab. 2. It is possible to observe that while the IMEP of the ethanol HCCI cylinder increased, the diesel fuel consumption (C_Diesel) was reduced while ethanol consumption (C_Ethanol) increased. Since the $10 \mathrm{~kW}$ load was kept constant from the generator side at $1800 \mathrm{rpm}$ when the HCCI cylinder load was increased, the two diesel cylinder load was automatically reduced by the stock generator set diesel engine speed governor. This behavior can also be noted at the relative air-fuel ratio $(\lambda)$ from the diesel cylinder, which was about 3.07 at $200 \mathrm{kPa}$ of IMEP load in the ethanol HCCI cylinder increased up to 4.7 at $600 \mathrm{kPa}$ of IMEP. The $\lambda$ for the HCCI cylinder presented the opposite trend: it tended to a richer mixture to increase ethanol HCCI cylinder load (IMEP).

The exhaust gas temperature (EGT) from the diesel cylinder and the HCCI cylinder intake temperature was well defined for each IMEP studied. The average intake temperatures for the HCCI cylinder were 147,133 , and $112^{\circ} \mathrm{C}$ for 200,400 , and $600 \mathrm{kPa}$ of IMEP, respectively. The amount of $\mathrm{CO}_{2}$ from diesel cylinder \#3 is also presented in Tab. 2. It can be seen that the $\mathrm{CO}_{2}$ emissions decrease, whereas the IMEP increase. The average $\mathrm{CO}_{2}$ emissions were about 43200, 35200, and 26900 ppm for 200, 400, and $600 \mathrm{kPa}$, respectively. The IMEP trade-off can explain this behavior between the HCCI and the diesel cylinders, where one cylinder compensated the other to maintain the electric load of $10 \mathrm{~kW}$ constant. In this regard, when HCCI the cylinder presented low IMEP, the diesel cylinder has a higher load, meaning a higher in-cylinder temperature, easing the $\mathrm{CO}$ to $\mathrm{CO}_{2}$ oxidation processes, resulting in higher $\mathrm{CO}_{2}$ emissions. However, the $\mathrm{CO}_{2}$ did not show a specific trend when CA50 increased.

The higher amount of water injected was at 200 $\mathrm{kPa}$ of IMEP, it can be attributed to the higher temperature of exhaust gases from the diesel cylinder. In this regard, a greater amount of water injected was needed than other loads to reduce the intake temperature and achieve the desired CA50. It is also possible to notice in Tab. 2 that for $200 \mathrm{kPa}$ of IMEP, 
as the CA50 increases, the consumption of ethanol and the amount of water injected also increase, thus reducing ethanol's lambda. However, this behavior is not observed for 400 and $600 \mathrm{kPa}$ of IMEP, where the quantity of ethanol and water injected remained practically constant, regardless of the stipulated CA50.

Table 2. Operating conditions of the experiment.

\begin{tabular}{|c|c|c|c|c|c|c|c|c|c|}
\hline $\begin{array}{l}\text { IMEP } \\
\text { HCCI } \\
\text { Cyl \#1 }\end{array}$ & $\begin{array}{c}\text { CA50 } \\
\text { (CAD) }\end{array}$ & $\begin{array}{c}\text { C_Diesel } \\
\text { Cyl \#3 } \\
(\mathrm{g} / \mathrm{s})\end{array}$ & $\begin{array}{c}\text { C_Ethanol } \\
(\mathrm{g} / \mathrm{s})\end{array}$ & $\underset{(\mathrm{g} / \mathrm{s})}{\mathrm{C} \text { H2O }}$ & $\begin{array}{c}\lambda \\
\text { Ethanol }\end{array}$ & $\begin{array}{c}\lambda \\
\text { Diesel }\end{array}$ & 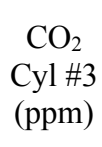 & $\begin{array}{c}\text { EGT } \\
\text { Cyl \#3 } \\
\left({ }^{\circ} \mathrm{C}\right)\end{array}$ & $\begin{array}{c}\text { Intake } \\
\text { Temp } \\
\text { HCCI Cyl } \\
\# 1\left({ }^{\circ} \mathrm{C}\right)\end{array}$ \\
\hline \multirow{4}{*}{$\begin{array}{l}200 \\
\mathrm{kPa}\end{array}$} & 2 & 0.36 & 0.48 & 1.49 & 1.52 & 3.07 & 43436 & 345 & 149 \\
\hline & 4 & 0.37 & 0.51 & 1.61 & 1.49 & 3.09 & 41703 & 345 & 146 \\
\hline & 6 & 0.36 & 0.55 & 1.65 & 1.43 & 3.04 & 40403 & 349 & 144 \\
\hline & 8 & 0.37 & 0.59 & 1.76 & 1.40 & 3.07 & 43251 & 350 & 147 \\
\hline \multirow{4}{*}{$\begin{array}{l}400 \\
\mathrm{kPa}\end{array}$} & 2 & 0.31 & 0.69 & 1.28 & 1.40 & 3.67 & 35401 & 312 & 136 \\
\hline & 4 & 0.31 & 0.69 & 1.34 & 1.40 & 3.67 & 35991 & 311 & 134 \\
\hline & 6 & 0.32 & 0.70 & 1.34 & 1.41 & 3.78 & 33964 & 307 & 130 \\
\hline & 8 & 0.33 & 0.71 & 1.31 & 1.40 & 3.76 & 35542 & 307 & 133 \\
\hline \multirow{4}{*}{$\begin{array}{l}600 \\
\mathrm{kPa}\end{array}$} & 2 & 0.26 & 0.99 & 0.86 & 1.18 & 4.45 & 29161 & 262 & 112 \\
\hline & 4 & 0.20 & 1.00 & 0.88 & 1.19 & 4.60 & 26595 & 262 & 109 \\
\hline & 6 & 0.20 & 0.97 & 0.81 & 1.23 & 4.84 & 25679 & 261 & 115 \\
\hline & 8 & 0.19 & 0.98 & 0.84 & 1.22 & 4.79 & 26109 & 261 & 112 \\
\hline
\end{tabular}

Fig. 2 shows the in-cylinder pressure traces and apparent heat release rate (AHRR) for HCCI combustion at different IMEP and CA50. The rate of apparent heat release is plotted on the secondary axes of Fig. 2. For all plots, the trace with the highest maximum pressure and heat release rate corresponds to the operating condition with two crank angle degrees (CAD) of CA50. The lowest maximum pressure and heat release rate correspond to $8 \mathrm{CAD}$ of CA50. The maximum pressure for 200, 400, and $600 \mathrm{kPa}$ of IMEP and 2 CAD of CA50 were 5330 6900 and $8530 \mathrm{kPa}$, respectively. It can be noticed from Fig. 2 that maximum pressure and heat release rate decrease with an increase in CA50. It is attributed to the change in volume since the volume increase with the increase in CA50. The pressure has the opposite effect.

Fig. 3 illustrates in detail the AHRR analysis, showing the CA10 and CA10-90 parameters. Fig. 3 (a) shows CA10 parameters, which correspond to a crank angle position for $10 \%$ of mass burn fraction, indicating the start combustion, and Fig. 3 (b) shows the CA10-90 parameter, which indicates the combustion duration. It can be noticed from Fig. 3 (a) that on increasing CA50, the combustion starts later, especially at 400 and $600 \mathrm{kPa}$ of IMEP. However, the curve practically was constant at $200 \mathrm{kPa}$ of IMEP with 7 CAD of CA10. It is observed that the combustion for $200 \mathrm{kPa}$ of IMEP started before than other IMEPs. In HCCI combustion, the start of combustion depends on chemical kinetics, which depends on the pressure and temperature history inside the combustion chamber.
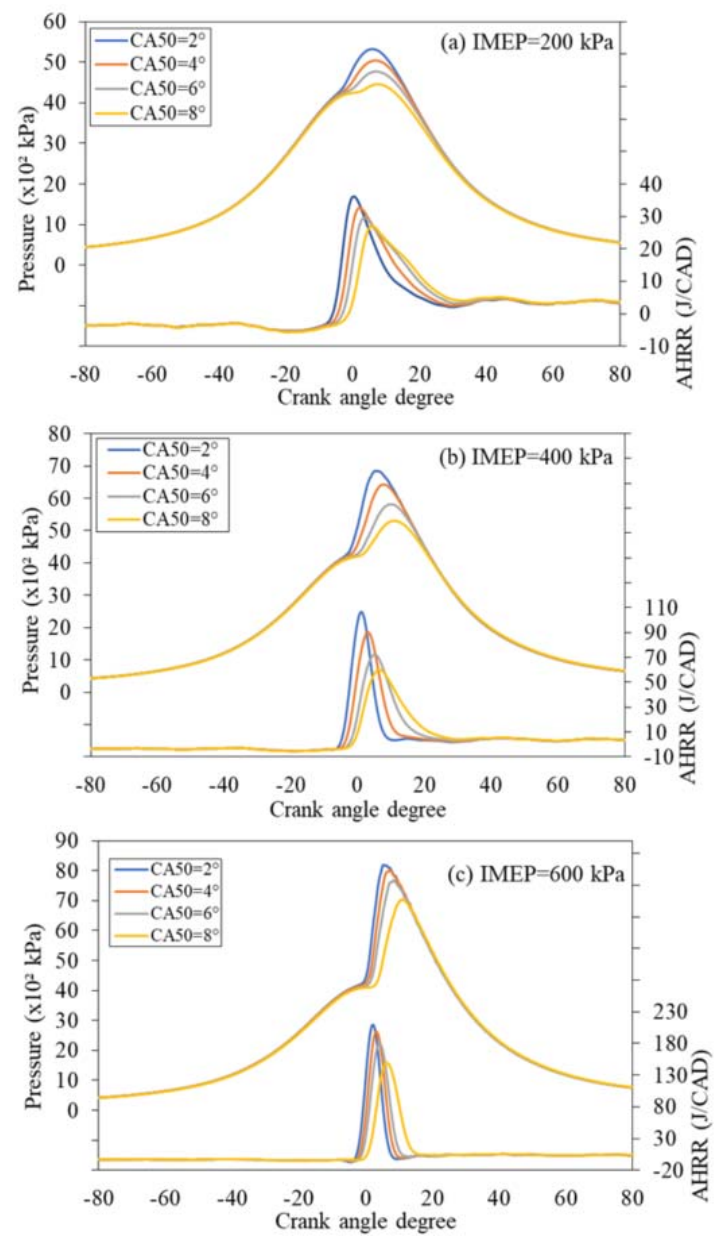

Figure 2. In-cylinder pressure trace and apparent heat release rate (AHRR) for different IMEPs and CA50. 

(a) IMEP $=200 \mathrm{kPa}$, (b) IMEP= $400 \mathrm{kPa}$, (c) IMEP=
$600 \mathrm{kPa}$.
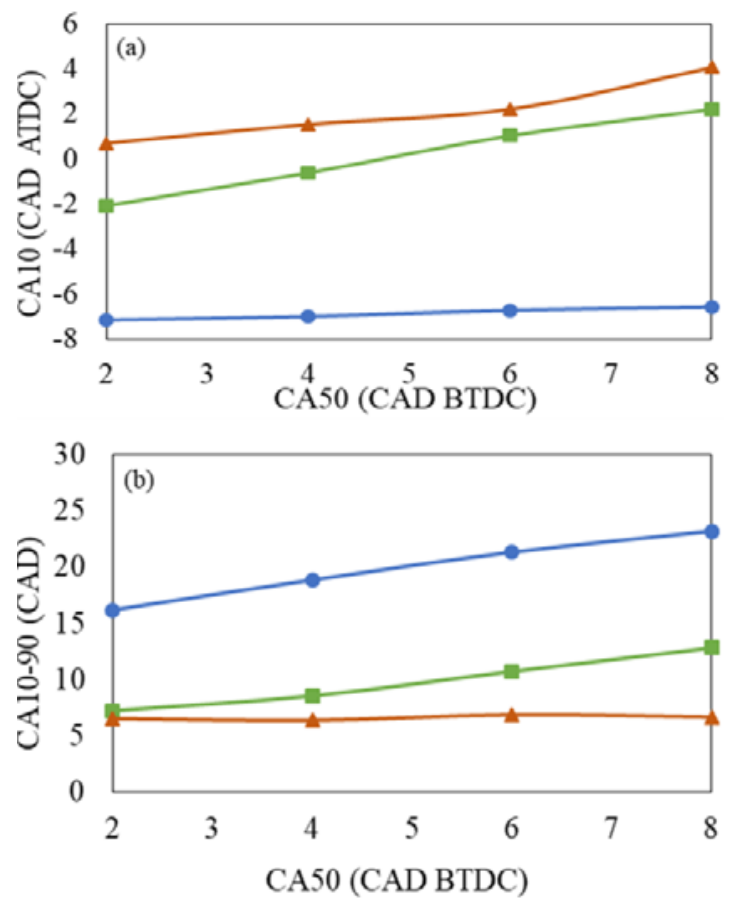

$\multimap-\mathrm{IMEP}=2$ bar $\rightarrow-\mathrm{IMEP}=4$ bar $\leadsto-\mathrm{IMEP}=6 \mathrm{bar}$

Figure 3. Effect of CA50 and IMEP on CA10 (a) and CA10-90 (b).

In this regard, the combustion for $200 \mathrm{kPa}$ of IMEP started before other loads due to a higher intake temperature than 400 and $600 \mathrm{kPa}$. From Fig. 3 (b), it is possible to observe that the combustion duration increased when CA50 increased, except for $600 \mathrm{kPa}$ of IMEP that stayed constant at around 6.7 CAD. The shortest combustion duration was 6.4 CAD at $600 \mathrm{kPa}$ of IMEP and 2 CAD of CA50. The highest combustion duration was achieved for 200 $\mathrm{kPa}$ of IMEP, 16.2 CAD at $2 \mathrm{CAD}$ of CA50, and increased to $23.2 \mathrm{CAD}$ at $8 \mathrm{CAD}$ of $\mathrm{CA} 50$, representing an increase of about $43 \%$.

The indicated fuel conversion efficiency for different IMEP and CA50 is shown in Fig. 4. It is observed that the indicated fuel conversion efficiency is lower for higher CA50 positions, except for 600 $\mathrm{kPa}$ of IMEP that showed an increasing tendency. In the present study, the maximum indicated fuel conversion efficiency was $36.9 \%$ achieved for 600 $\mathrm{kPa}$ of IMEP and 8 CAD of CA50. However, at 600 $\mathrm{kPa}$ of IMEP, the indicated efficiency was very similar in all points. The higher indicated efficiency at $600 \mathrm{kPa}$ of IMEP compared to other IMEPs can be attributed to the constant and fast combustion duration for all CA50 tested. In this regard, when combustion starts, the energy is released in a very short period, reducing the time of heat transfer between the gases and the cylinder walls, resulting in a reduction of the heat losses and, consequently, increasing efficiency. At $200 \mathrm{kPa}$ of IMEP, the indicated fuel conversion efficiency was $25.9 \%$ at 2 CAD of CA50 and decreased to $18.5 \%$, representing a reduction about $28 \%$. It can be attributed to a high combustion duration and possible combustion instability.

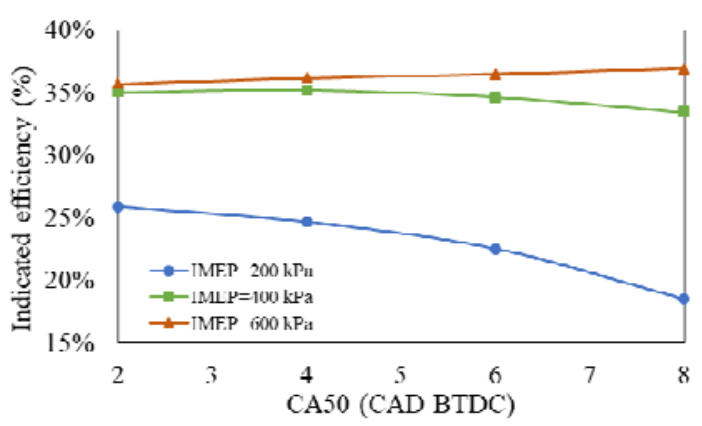

Figure 4. Indicated fuel conversion efficiency for different CA50 and IMEP.

The fluctuation of IMEP is used as a definition of cycle-to-cycle variations and expressed as a coefficient of variation (COV) of IMEP. The coefficient of variation was calculated as described in Maurya and Agarwal (2011). This coefficient is an important parameter that shows whether combustion is occurring stable without excessive behavioral variations in each cycle. Heywood (2018) provides a reference of a maximum value of $5 \%$ for $\mathrm{COV}$. It is important to maintain this parameter below the reference value to avoid drivability problems in automobiles, which generally arise when $\mathrm{COV}_{\text {IMEP }}$ exceeds $5 \%$.

Fig. 5 shows $\mathrm{COV}_{\text {IMEP }}$ for 100 consecutive cycles at each test condition in HCCI combustion. It can be noticed that $\mathrm{COV}_{\text {IMEP }}$ for 400 and $600 \mathrm{kPa}$ of IMEP stayed below the reference value. At $600 \mathrm{kPa}$, the $\mathrm{COV}_{\text {IMEP }}$ resulted in very low values, varying between $0.97 \%$ to $1.16 \%$. The $\mathrm{COV}_{\text {IMEP }}$ values for $400 \mathrm{kPa}$ kept very similar until 6 CAD of CA50. For $8 \mathrm{CAD}$ of CA50, the $\mathrm{COV}_{\text {IMEP }}$ increased to $3.72 \%$. However, at $200 \mathrm{kPa}$ of IMEP, all points were above the maximum reference value of $5 \%$. For $200 \mathrm{kPa}$ of IMEP and 2 CAD of CA50, the COV was $5.16 \%$, and the highest value was $19.5 \%$ achieved for CA50 of 8 CAD. This result demonstrated that the engine operated in an unstable manner in most of the tests at 2 bar of IMEP, presenting misfire, mainly with higher angles of CA50. One hypothesis for these results are the low in-cylinder temperature caused by the large amount of water injected to control combustion phasing, the operation of the engine at a low load and delayed combustion timing. Therefore, the complete burning of the charge was more difficult, resulting in misfire. 


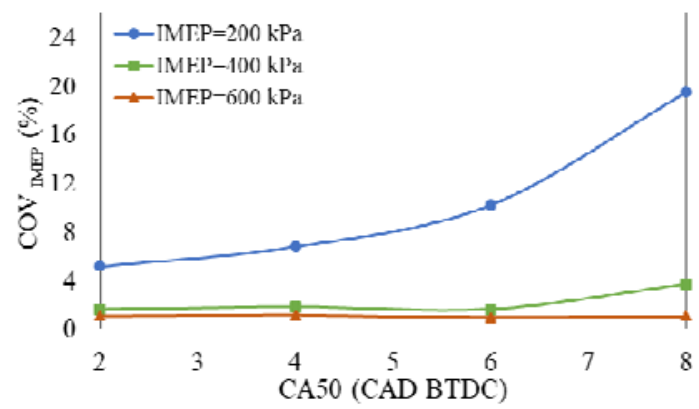

Figure 5. Variation of $\mathrm{COV}_{\mathrm{IMEP}}$ for different CA50 and IMEP.

Fig. 6 shows that the experimental data indicated specific emissions of HC. It is apparent from this figure that $200 \mathrm{kPa}$ of IMEP showed higher $\mathrm{HC}$ emissions compared to 400 and $600 \mathrm{kPa}$ of IMEP. The highest ISHC found was about 51.2 $\mathrm{g} / \mathrm{kWh}$ for $200 \mathrm{kPa}$ of IMEP and $8 \mathrm{CAD}$ of CA50. The expressive increase in $\mathrm{HC}$ emissions at $200 \mathrm{kPa}$ of IMEP is attributed to unstable combustion, leading to misfire, and not burning all the fuel during the expansion stroke, which leads to an increase in $\mathrm{HC}$ emissions. The lowest ISHC emissions were found for $600 \mathrm{kPa}$ of IMEP, resulting in a values between 4.7 to $6.0 \mathrm{~g} / \mathrm{kWh}$. However, at $4 \mathrm{CAD}$ of CA50, the ISHC emissions of 400 and $600 \mathrm{kPa}$ of IMEP were practically the same. After this point, ISHC emissions were higher for $400 \mathrm{kPa}$ of IMEP.

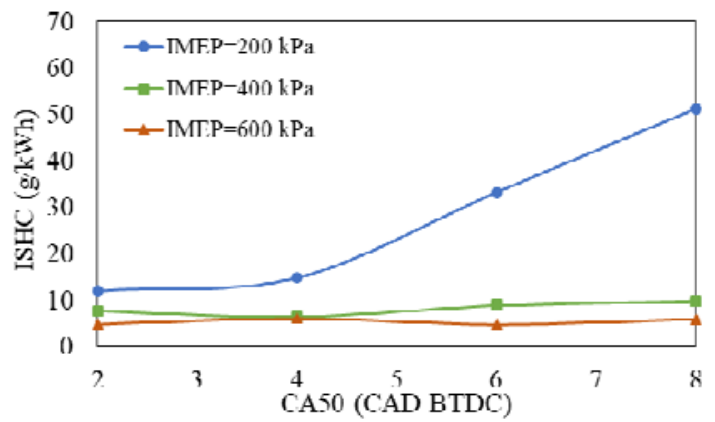

Figure 6. Indicated specific emissions of $\mathrm{HC}$ at different CA50 and IMEP.

The results obtained from the experimental data of the indicated specific emissions of $\mathrm{CO}$ are shown in Fig. 7. The graph shows that there has been an increase in ISCO emissions when CA50 increase. It can also be noticed that ISCO emissions were higher for lower IMEPs studied. The highest ISCO emissions were found for $200 \mathrm{kPa}$ of IMEP, resulting in $73.7 \mathrm{~g} / \mathrm{kWh}$ at 2 CAD of CA50 and $114.2 \mathrm{~g} / \mathrm{kWh}$ at $8 \mathrm{CAD}$ of CA50. The ISCO emissions for $600 \mathrm{kPa}$ of IMEP were the lowest, varying from 2.4 to 4.3 $\mathrm{g} / \mathrm{kWh}$. These results may be explained by the lower in-cylinder temperature of low IMEPs, and high CA50 studied, being difficult to have complete combustion, making the complete oxidation of $\mathrm{CO}$ to $\mathrm{CO}_{2}$ difficult.

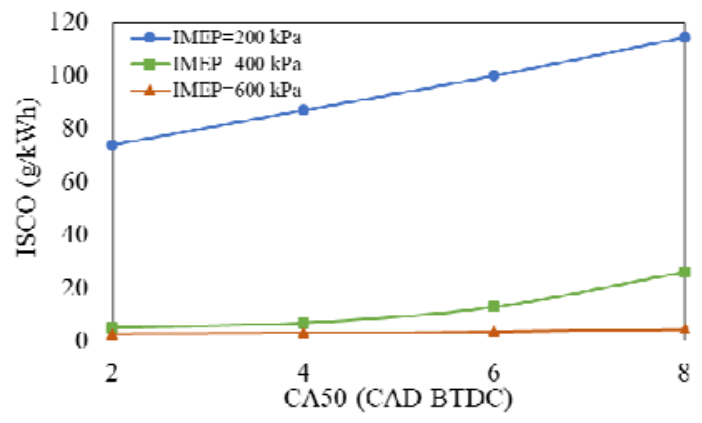

Figure 7. Indicated specific emissions of $\mathrm{CO}$ at different CA50 and IMEP.

Fig. 8 presents the indicated specific emissions of $\mathrm{NO}_{\mathrm{X}}$ for different IMEP and CA50 analyzed. From the figure, it can be seen that all points were below $4.7 \mathrm{~g} / \mathrm{kWh}$. We can see that $200 \mathrm{kPa}$ of IMEP at 2 CAD of CA50 resulted in the highest value of $\mathrm{ISNO}_{\mathrm{X}}$. The $\mathrm{NO}_{\mathrm{X}}$ emissions for 200 and $600 \mathrm{kPa}$ of IMEP tended to decrease with the increase in CA50. The lowest value reported was $1.46 \mathrm{~g} / \mathrm{kWh}$ for 600 $\mathrm{kPa}$ of IMEP and $8 \mathrm{CAD}$ of CA50, representing a reduction about $38 \%$ compared to $2 \mathrm{CAD}$ of CA50. However, at $400 \mathrm{kPa}$ of IMEP, no significant differences were found between $2 \mathrm{CAD}$ and $8 \mathrm{CAD}$ of CA50.

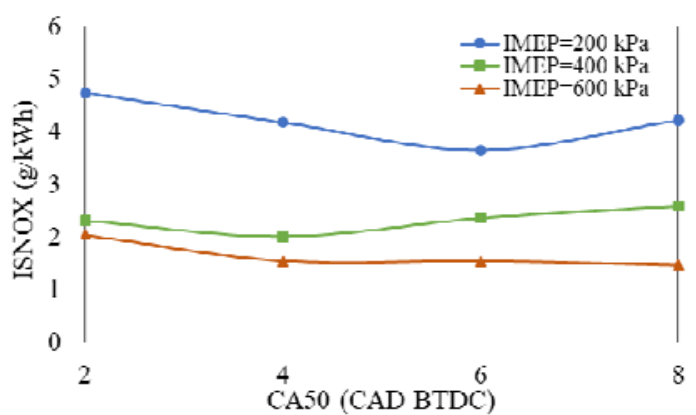

Figure 8. Indicated specific emissions of $\mathrm{NO}_{\mathrm{X}}$ at different CA50 and IMEP.

\section{CONCLUSIONS}

This paper studied the HCCI combustion of ethanol to a dedicated cylinder of a three-cylinder diesel power generation set. The cylinder \#1 operates with ethanol in HCCI combustion, and cylinder \#3 was used as a heat source to cylinder \#1 via total recirculation of exhaust gases. The water injection was used to control the combustion, especially the CA50 parameter. In this regard, four CA50 values were experimented alongside different IMEP. Parameters related to performance, combustion, and exhaust emission characteristics were evaluated.

It was noticed an increasing trend in the start and duration of combustion, whereas the CA50 increased. The lowest combustion duration was about 
6.5 CAD for $600 \mathrm{kPa}$ of IMEP. On the other hand, the highest combustion duration was found at 200 $\mathrm{kPa}$ IMEP, which increase from 16.2 CAD to 23.2 $\mathrm{CAD}$. The indicated fuel conversion efficiency showed a decreasing trend, while CA50 increased, and IMEP decreased. However, at $600 \mathrm{kPa}$ of IMEP, the opposite trend was, indicating that the efficiency increased while CA50 increased. Indicated fuel conversion efficiency values of up to $35.7 \%$ were found for $600 \mathrm{kPa}$ of IMEP, but for $200 \mathrm{kPa}$ of IMEP, the indicated efficiency was significantly deteriorated, resulting in values between 18.5 and $25.9 \%$.

The $\mathrm{COV}_{\text {IMEP }}$ was found below the maximum reference value of $5 \%$ at 400 , and $600 \mathrm{kPa}$ of IMEP for all CA50 tested. At $200 \mathrm{kPa}$ of IMEP, COV IMEP was very close to $5 \%$ at 2 CAD of CA50, but for 8 CAD achieved the highest value of $19.5 \%$. Indicated specific carbon monoxide and hydrocarbon emissions tended to increase with increasing CA50. For all plots, the $\mathrm{NO}_{\mathrm{X}}$ emissions were below $4.7 \mathrm{~g} / \mathrm{kWh}$. In general, the $\mathrm{NO}_{\mathrm{X}}$ emissions tended to decrease whereas CA50 increase, although it did not occur for $400 \mathrm{kPa}$ of IMEP. The lowest values were found for $600 \mathrm{kPa}$ of IMEP, achieving the value of $1.46 \mathrm{~g} / \mathrm{kWh}$.

Overall, the results were satisfactory, showing the potential for water injection to control the combustion in HCCI engines. It is important to highlight that the HCCI combustion was only possible using the water injection. Otherwise, the HCCI combustion tended to start before TDC, resulting in knocking. In this regard, the results showed the potential for water injection to mitigate the knock in HCCI engines. At 400 and $600 \mathrm{kPa}$ of IMEP, the results indicated a good combustion stability, efficiency, and emissions characteristics, demonstrating the water injection potential. However, at low load, the engine operated in an unstable manner, presenting misfire and a low indicated efficiency.

\section{ACKNOWLEDGEMENTS}

The authors thank CNPQ and CAPES for the financial support.

\section{REFERENCES}

Agarwal, A. K., Singh, A. P. and Maurya, R. K., 2017, Evolution, challenges and path forward for low temperature combustion engines, Progress in Energy and Combustion Science, Vol. 61, pp. 1-56.

Ahari, M. F. and Neshat, E., 2019, Advanced analysis of various effects of water on natural gas HCCI combustion, emissions and chemical procedure using artificial inert species, Energy, Vol. 171, pp. 842-852.

Bendu, H. and Murugan, S., 2014, Homogeneous charge compression ignition (HCCI) combustion: Mixture preparation and control strategies in diesel engines, Renewable and Sustainable Energy Reviews, Vol. 38, pp. 732-746.

Heywood, J. B., 2018. Internal Combustion Engine Fundamentals. McGraw-Hill, New York, 2nd edition.

International Energy Agency, 2019a " $\mathrm{CO}_{2}$ Emissions From Fuel Combustion".

International Energy Agency, 2019b "Oil Information - Overview".

Iwashiro, Y., Tsurushima, T., Nishijima, Y., Asaumi, Y. and Aoyagi, Y., 2002, Fuel Consumption Improvement and Operation Range Expansion in HCCI by Direct Water Injection, SAE Technical Papers, Vol. 01-105.

Krishnamoorthi, M., Malayalamurthi, R., He, Z. and Kandasamy, S., 2019, A Review on Low Temperature Combustion engines: Performance, Combustion and Emission Characteristics, Renewable and Sustainable Energy Reviews, Vol. 116, pp. 109404.

Martins, M., Fischer, I., Gusberti, F., Sari, R., and Dalla Nora, M., 2017, HCCI of Wet Ethanol On a Dedicated Cylinder of a Diesel Engine, SAE Technical Paper, No. 01-0733.

Maurya, R. K. and Agarwal, A. K., 2011, Experimental Study of Combustion and Emission Characteristics of Ethanol Fuelled Port Injected Homogeneous Charge Compression Ignition (HCCI) Combustion Engine, Applied Energy, Vol. 88, No. 4, pp. 1169-1180.

Mittal, M., Donahue, R., Winnie, P. and Gillette, A., 2015, Exhaust Emissions Characteristics of a Multi-Cylinder 18.1-L Diesel Engine Converted to Fueled With Natural Gas and Diesel pilot, Journal of the Energy Institute, Vol. 88, No. 3, pp. 275-283.

Punov, P., Evtimov, T., Chiriac, R., Clenci, A., Danel, Q. and Descombes, G., 2017, Progress in High Performance, Low Emissions, and Exergy Recovery in Internal Combustion Engines, International Journal of Energy Research, Vol. 41, No. 9, pp. 1229-1241.

Rosa, J. S., Altafini, C. R., Wander, P. R., Telli, G. D., and Rocha, L. A. O., 2019, Wet Ethanol Fumigation on a Compression Ignition Engine: Effects of Air Intake Throttled, Journal of the Brazilian Society of Mechanical Sciences and Engineering, 41(11), 500.

Saxena, S. and Bedoya, I. D., 2013, Fundamental Phenomena Affecting Low Temperature Combustion and HCCI Engines, High Load Limits and Strategies for Extending These Limits, Progress in Energy and Combustion Science, Vol. 39, No. 5, pp. 457-488.

Srivastava, D. K., Agarwal, A. K., Datta, A. and Maurya, R. K., 2018, Advances in Internal Combustion Engine Research. Springer, Singapore.

U.S. Energy Information Administration, 2015, Annual Energy Outlook 2015, Vol. 1, pp. 1-244.

Vailatti, M. A., Altafini, C. R., Telli, G. D., and Rosa, J. S., 2017, Experimental Analysis of a Small Generator Set Operating on Dual Fuel Diesel- 
Ethanol, Scientia cum Industria, Vol. 5, No. 1, pp. 19.

Valero-marco, J., Lehrheuer, B., López, J. J. and Pischinger, S., 2018, Potential of Water Direct Injection in a CAI/HCCI Gasoline Engine to Extend the Operating Range Towards Higher Loads, Fuel, Vol. 231, pp. 317-327. 